\title{
Factors Predictive of Obliteration After Arteriovenous Malformation Radiosurgery
}

\author{
C. Herbert, V. Moiseenko, M.McKenzie, G. Redekop, F. Hsu, E. Gete, B. Gill, \\ R. Lee, K. Luchka, A. Lee, C. Haw, B. Toyota, M. Martin
}

\begin{abstract}
Objective: To investigate predictive factors of complete obliteration following treatment with linac-based stereotactic radiosurgery for intracerebral arteriovenous malformations. Methods: Archived plans for 48 patients treated at the British Columbia Cancer Agency and who underwent post-treatment digital subtraction angiography to assess obliteration were studied. Actuarial estimates of obliteration were calculated using the Kaplan-Meier method. Univariate and multivariate Cox proportional hazards models were used for analysis of incidence of obliteration. Log-rank test was used to search for parameters associated with obliteration. Results: Complete nidus obliteration was achieved in 38/48 patients (79.2\%). Actuarial rate of obliteration was $75.9 \%$ at 4 years $(95 \%$ confidence interval $63.1 \%-88.6 \%)$. On univariate analysis, prescribed dose to the margin $(\mathrm{p}=0.002)$ and dose to isocentre $(\mathrm{p}=0.022)$ showed statistical significance. No parameters were significant in a multivariate model. According to the log-rank test, prescribed dose to the margin of $>20$ Gy $(p=0.004)$ and dose to the isocentre of $>25$ Gy $(p=0.004)$ were associated with obliteration. Conclusion: Reported series in the literature suggest a number of different factors are predictive of complete obliteration of arteriovenous malformations following radiosurgery. However, differing definitions of volume and complete obliteration makes direct comparison between series difficult. This study demonstrates that complete obliteration of the nidus following linear accelerator-based stereotactic radiosurgery for arteriovenous malformations appears to be most closely related to the prescribed marginal dose. In particular, a marginal dose of $>20 \mathrm{~Gy}$ is strongly associated with obtaining complete obliteration of the nidus.
\end{abstract}

RÉSUMÉ: Facteurs de prédiction de l'oblitération par la radio chirurgie de malformations artérioveineuses. Objectif : Le but de l'étude était de déterminer quels sont les facteurs de prédiction d'une oblitération complète de malformations artérioveineuses intracérébrales suite au traitement par radio chirurgie stéréotaxique par Linac. Méthodes : Nous avons étudié le plan de traitement de 48 patients, qui ont subi une angiographie de soustraction numérique après traitement au British Columbia Cancer Agency, pour évaluer l'oblitération. L'estimation actuarielle de l'oblitération a été calculée au moyen de la méthode de Kaplan-Meier. Nous avons utilisé le modèle de régression univarié et multivarié des risques proportionnés de Cox pour analyser l'incidence de l'oblitération. Le test de rang a été utilisé pour identifier les paramètres associés à l'oblitération. Résultats : L'oblitération complète du foyer morbide a été réalisée chez 38 des 48 patients $(79,2 \%)$. Le taux actuariel d'oblitération était de 75,9\% après 4 ans (intervalle de confiance à $95 \%$ de $63,1 \%$ à 88,6\%). À l'analyse univariée, la dose prescrite en périphérie $(\mathrm{p}=0,002)$ et la dose à l'isocentre $(\mathrm{p}=0,022)$ étaient significatives au point de vue statistique. Aucun paramètre n'était significatif à l'analyse multivariée. Au test de rang, la dose de $>20$ Gy $(p=0,004)$ en périphérie et la dose de $>25$ Gy $(\mathrm{p}=0,004)$ à l'isocentre étaient associées à l'oblitération. Conclusion : Les séries de patients rapportées dans la littérature suggèrent différents facteurs de prédiction de l'oblitération complète des MAV par radio chirurgie. Cependant, des définitions différentes du volume de la MAV et de son oblitération complète rendent difficile la comparaison directe entre les séries. Cette étude démontre qu'une oblitération complète du foyer morbide d'une MAV après traitement par radio chirurgie stéréotaxique semble être étroitement reliée à la dose marginale prescrite. Une dose marginale de $>20$ Gy est fortement associée à une oblitération complète du foyer morbide.

Can. J. Neurol. Sci. 2011; 38: 845-850

Intracranial arteriovenous malformations (AVMs) are congenital lesions consisting of focal areas of abnormal dilated arteries and veins within the brain parenchyma. Small arterioles within the AVM have an absent smooth muscle layer and lack a capillary bed ${ }^{1}$. This results in arteriovenous shunting through one or more fistulae. This direct shunting leads to a risk of venous rupture due to the high pressures involved with potentially devastating consequences ${ }^{2}$. The prevalence of intracranial arteriovenous malformation in the general population is estimated to be anywhere between $0.001 \%$ and $0.52 \%{ }^{3-6}$. Typically patients present following an intracerebral haemorrhage $(42-72 \%)$, most commonly between the ages of 20 and 40 years $^{3,7-10}$. Other presenting symptoms include seizures, consequences of mass effect and isolated headache ${ }^{2}$. However, with modern imaging techniques we are seeing an increasing number of patients with asymptomatic arteriovenous malformations.

From the Department of Radiation Oncology (CH, MMc), Department of Medical Physics (VM, EG, BG, RL, KL), Department of Medical Imaging (MM), British Columbia Cancer Agency; Division of Neurosurgery (GR, CH, BT), Vancouver General Hospital, Vancouver; Department of Neurosurgery (AL), Royal Columbian Hospital, New Westminster; Department of Radiation Oncology (FH), British Columbia Cancer Agency, Abbotsford, British Columbia, Canada.

Received April 7, 2011. Final Revisions Submitted May 16, 2011.

Correspondence to: C. Herbert, Department of Radiation Oncology, BC Cancer Agency, 600 West 10th Avenue, Vancouver, British Columbia, V5Z 4E6, Canada. 
Treatment options for AVMs include surgery, embolization, stereotactic radiosurgery (SRS) or a combination of these modalities. Although there are no randomised trials to aid decision making, the American Stroke Association has published recommendations ${ }^{11}$. These are largely based on the SpetzlerMartin grading scale ${ }^{12}$, a simple system devised to predict the risk of morbidity and mortality following neurosurgery for AVMs. Lesions are graded on the basis of size, pattern of venous drainage and neurological eloquence of adjacent brain. Radiosurgery is generally recommended for lesions in anatomical locations that may be associated with an increased risk of surgical complications. This is particularly the case for AVMs in eloquent regions of the brain, owing to their anatomic location or feeding-vessel anatomy, where surgical resection is likely to result in neurologic deficits. The goal of SRS is to induce complete luminal obliteration thereby preventing future haemorrhage. Initial studies demonstrated the effectiveness of Gamma Knife SRS ${ }^{13-14}$. Subsequently, linear accelerator-based treatment has been shown to be equally effective ${ }^{15-19}$.

The British Columbia Cancer Agency (BCCA) has been treating intracerebral AVMs using single-fraction linear accelerator-based SRS since 1997. Patients with intracranial AVMs who may be candidates for SRS are reviewed by a multidisciplinary group. This group is comprised of radiation oncologists, neurosurgeons, and a neuroradiologist who make up the precision radiotherapy team at BCCA. The feasibility of each treatment modality is discussed, and management recommendations are made by the group. Typically, SRS is recommended for lesions unsuitable for embolization and/or surgery or for residual AVMs after unsuccessful embolization and/or surgery. The aim of this study was to investigate factors predictive of complete nidus obliteration following treatment with linear accelerator-based SRS.

\section{Materials AND Methods}

Between 25th September 1997 and 20th July 2006, 79 patients were treated with linear accelerator-based radiosurgery for intracerebral AVM. The cut-off date was selected to allow a minimum of four years follow-up. Fifty-six patients underwent digital subtraction angiography (DSA) to assess nidus obliteration following treatment. Of the 23 patients who did not undergo DSA, 19 had assessment by magnetic resonance imaging (MRI) alone, two were lost to follow-up, one required emergency surgery following a bleed post-SRS, and one died of an unrelated cause within three years of treatment. Archived plans were available for assessment in 52 out of the 56 patients who underwent DSA. A further four patients who had had prior treatment with either SRS or proton therapy were also excluded from analysis, leaving 48 patients for assessment. The study was approved by the institutional ethics committee.

\section{Radiosurgery technique}

All patients underwent digital subtraction angiography as well as an MRI scan prior to treatment. Patients were treated using an invasive stereotactic head frame (BrainLAB AG, Heimstetten, Germany) for use in performing the planning computed tomography (CT) scan and for radiosurgery. Target localization and definition of a reference coordinate system were provided by a stereotactic localizer box (BrainLAB AG, Heimstetten, Germany). Planning CT scans were done on a GE
Lightspeed RT16 scanner (GE Healthcare Inc., WI) with an axial image slice thickness of $1.25 \mathrm{~mm}$. The CT images were fused to both a digital subtraction angiogram and an axial PD-weighted MRI for anatomy and target delineation. The AVM nidus was contoured as the gross target volume. A $1.0 \mathrm{~mm} \mathrm{3-dimensional}$ margin around the contoured AVM was used for the planning target volume (PTV).

Treatment planning was performed using the BrainSCAN SRS treatment planning system (BrainLAB AG, Heimstetten, Germany). Prior to August 2000, plans consisted of multiple arcs using circular, cone-shaped collimators and 1-4 isocentres $(\mathrm{n}=$ 31). The median number of arcs was 8 (range, 4-16). After this date, most treatments were planned with non-coplanar static conformal fields using a Micro MLC ( $\mu$ MLC) (BrainLAB AG, Heimstetten, Germany) and a single isocentre $(n=17)$. The median number of fields using this approach was 5 (range, 4-18). Plans were normalized to $100 \%$ at the isocentre. An isodose contour conforming to the PTV was selected as the prescription isodose. For plans using multiple arcs, prescription was either to the $50 \%(n=12)$ or to the $80 \%$ isodose volume conforming to the PTV. In one case, prescription was to the $65 \%$ isodose. For plans using multiple static conformal fields, prescription was to the $80 \%$ isodose volume conforming to the PTV. Prescription to the $50 \%$ isodose was used for the majority of patients treated until 1999 , followed by a transition period when this prescription was used only occasionally. No patients treated since September 2001 had dose prescribed to the $50 \%$ isodose. Treatment was delivered using $6 \mathrm{MV}$ photons on a Varian CL21 EX linear accelerator (Varian Medical Systems Inc., Palo Alto, CA).

\section{Dose prescription}

The prescription dose was at the discretion of the treating physician and varied depending on AVM size, location and patient age. The median prescription dose to the PTV was $20 \mathrm{~Gy}$ (range, 12-25 Gy). The median dose to isocentre was $31.25 \mathrm{~Gy}$ (range 15-50 Gy). Forty-seven patients (97.9\%) were prescribed at least 16 Gy to the periphery of the PTV. One patient was prescribed 12 Gy: an AVM in the deep parietal lobe of a 21 yearold patient. The mean total dose for all patients was $29.8 \pm 7.5$ Gy at the isocentre.

\section{Follow-up evaluation}

All patients were scheduled for clinical follow-up after treatment. Routine follow-up involved annual MRI scans with digital subtraction angiogram deferred until MRI evidence of complete obliteration or until three to four years after treatment. Median time from treatment to angiogram was 29.8 months (range 12-68 months). Complete angiographic obliteration was defined as normal blood flow, absence of pathologic vessels at the site of the nidus, and normalization of flow in the draining veins.

\section{Statistical analysis}

Actuarial estimates of complete nidus obliteration were calculated using the Kaplan-Meier $\operatorname{method}^{20}$. Univariate and multivariate Cox proportional hazards models were used for analysis of complete obliteration. The following variables were examined in the univariate analysis: age, lesion location, Spetzler-Martin grade, lesion volume, lesion diameter (largest dimension), prescribed dose to the margin, and dose to the 
Table 1: Pre-treatment patient and AVM characteristics $(n=48)$

\begin{tabular}{lll}
\hline Age (years) & & Median 37 (range 10-72) \\
\hline Sex & Male & $21(43.8 \%)$ \\
& Female & $27(56.3 \%)$ \\
\hline ECOG performance & 0 & $18(37.5 \%)$ \\
status & 1 & $21(43.8 \%)$ \\
& 2 & $8(16.7 \%)$ \\
& 3 & 0 \\
\hline Smoker $(\mathrm{n}=32)$ & 4 & $1(2.1 \%)$ \\
\hline Diabetes $(\mathrm{n}=36)$ & & $12(37.5 \%)$ \\
\hline Hypertension $(\mathrm{n}=36)$ & & $1(2.8 \%)$ \\
\hline Symptoms prior to SRS & & $6(16.7 \%)$ \\
& bleeding & $29(60.4 \%)$ \\
& seizures & $13(27.1 \%)$ \\
\hline Extranidal aneurysm & headache & $4(8.3 \%)$ \\
\hline Spetzler-Martin grade & incidental finding & $2(4.2 \%)$ \\
(n=43) & & $5(10.4 \%)$ \\
& 1 & $1(2.3 \%)$ \\
& 2 & $10(23.3 \%)$ \\
\hline Lesion diameter $(\mathrm{mm})$ & 3 & $25(58.1 \%)$ \\
\hline Lesion volume $(\mathrm{cc})$ & 4 & $7(16.3 \%)$ \\
\hline AVM location & & Median 23.6 (range 9.9-53.4) \\
& & Median $2.5($ range $0.3-21.2)$ \\
\hline Prior treatment & deep & $10(20.8 \%)$ \\
& other & $38(79.2 \%)$ \\
\hline & surgery & $1(2.1 \%)$ \\
& embolization & $14(29.2 \%)$ \\
\hline & surgery + embolization & $1(2.1 \%)$ \\
\hline
\end{tabular}

Notes: "deep" location = basal ganglia, thalamus, brain stem; "other" location = frontal, parietal, temporal, occipital, intraventricular, cerebellar, corpus callosum (from Wegener et al ${ }^{21}$. Spetzler-Martin grade correlates with surgical outcome ${ }^{12}$. Partial data only was available for Spetzler-Martin grade, smokers, and prevalence of hypertension and diabetes mellitus.

isocentre. Log-rank test was used to search for dosimetric parameters associated with obliteration. The patient cohort was divided into two subgroups according to the value of the parameter. For continuous variables cut-off values were introduced in an incremental fashion. For example, if the parameter under consideration was lesion volume and a current cut-off value was $10 \mathrm{cc}$, group one comprised patients whose lesion volume was $>10 \mathrm{cc}$ and group two $\leq 10 \mathrm{cc}$. The difference in obliteration rates in these two groups was examined for statistical significance using log-rank test, and parameter values leading to $\mathrm{p}<0.05$ were recorded. Full ranges of values of the following dosimetric parameters were explored: lesion volume, lesion diameter, dose prescribed to the margin, and dose to the isocentre. Dose to the margin/lesion volume combinations were also tested for their association with obliteration rates using the log-rank test. In this analysis one subgroup comprised patients receiving a certain dose or larger and having lesion volume of certain size or smaller. The other subgroup comprised patients who had at least one of these conditions not fulfilled. Statistical analyses were undertaken using Statistica (Statsoft, Tulsa, OK).

\section{RESULTS}

Pre-treatment patient characteristics are shown in Table 1. The anatomic locations of the AVMs were as follows: four frontal, eight parietal, ten temporal, seven occipital, seven cerebellar, one ventricular, and one corpus callosum. There were ten patients with an AVM in a "deep" location. Deep locations included basal ganglia (1), thalamus (6), and brainstem (3). The most common presenting symptom was intracerebral haemorrhage $(60.4 \%)$. Seventeen patients $(35.4 \%)$ had been previously treated either by surgery or embolization or a combination of these modalities. Median follow-up was 41 months (range 24-139 months).

Thirty-eight patients (79.2\%) had complete obliteration of the AVM nidus on angiogram following treatment. Kaplan-Meier actuarial complete obliteration rate was $75.9 \%$ (95\% confidence interval $63.1 \%-88.6 \%$ ) at four years. The Kaplan-Meier curve for proportion of patients failing to achieve complete obliteration is shown in Figure 1. For plans prescribed to the 50\% isodose, the crude rate of obliteration was $75 \%$ and for plans prescribed to the $80 \%$ isodose, $80.0 \%$. There were insufficient patients, however, treated to the $50 \%$ isodose $(n=12)$ to perform statistical analysis.

Table 2 shows the results of the univariate and multivariate analyses. When the parameters in Column 1 were entered into the Cox proportional hazards model one at a time, prescribed dose to the margin and the dose to the isocentre showed statistical significance. Lesion volume and diameter did not show statistical significance. In a multivariate analysis, none of the parameters were statistically significant.

Figure 2 shows the distribution of obliterated and nonobliterated AVMs according to prescribed dose and both lesion diameter and lesion volume. The AVMs that failed to obliterate 


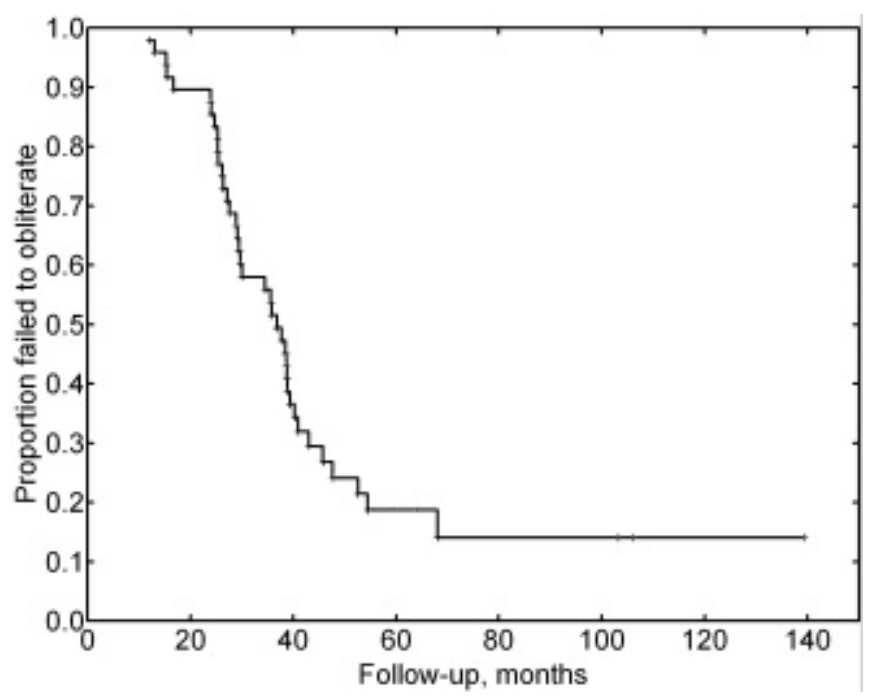

Figure 1: Actuarial proportion of patients who failed to obliterate.

following treatment were generally associated with lower marginal doses and greater lesion diameters and volumes.

Table 3 shows the results of searching for cut-off values using the log-rank test. Prescribed dose to the margin $(\mathrm{p}=0.004)$, and dose to the isocentre $(p=0.004)$ were associated with an increased incidence of complete nidus obliteration. Lesion volume was only marginally significant $(p=0.048)$. According to the log-rank test, the cut-off value for prescribed dose was $>20$ $\mathrm{Gy}$, for dose to the isocentre $>25 \mathrm{~Gy}$, and for lesion volume $>6.4$ cc. The Kaplan-Meier curves of complete obliteration for prescribed dose to the margin $\leq 20$ Gy and $>20$ Gy are shown in Figure 3.

The log-rank test was also performed for a variety of prescription dose/lesion volume combinations. The strongest association was found for prescription dose equal to or larger than 20 Gy and lesion volume of $10 \mathrm{cc}$ or less, with an actuarial rate of obliteration of $91.6 \%$. If one of these conditions was not met, the obliteration rate was $60.9 \%(\mathrm{p}=0.033)$.

\section{Discussion}

The results from this series of 48 patients treated for AVMs with linear accelerator-based SRS are consistent with other series
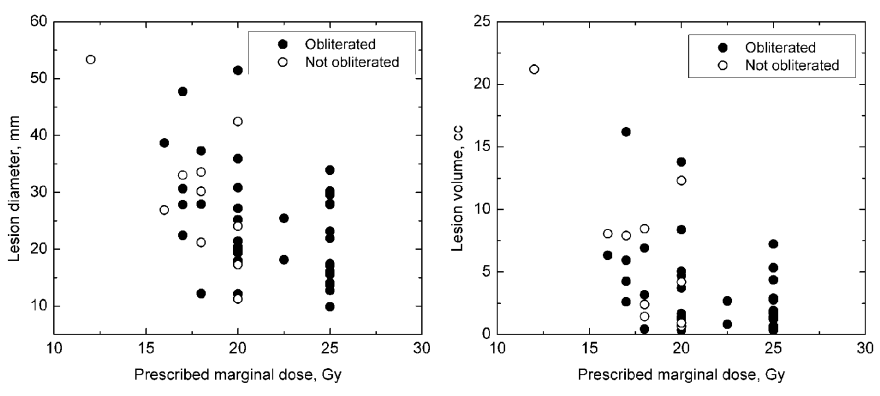

Figure 2: Outcomes following treatment according to prescribed marginal dose, lesion diameter and lesion volume.

reported in the literature which suggest complete nidus obliteration in $60-90 \%$ of patients ${ }^{15,22-26}$. The AVMs were initially treated with Gamma Knife radiosurgery ${ }^{13}$. Lunsford et $\mathrm{al}^{14}$ published a complete obliteration rate of $80 \%$ at two years in 46 patients undergoing Gamma Knife radiosurgery. Flickinger et $\mathrm{al}^{25}$ demonstrated a complete obliteration rate of $72 \%$ with three year angiographic follow-up in 197 patients. Meanwhile, Pollock et $\mathrm{al}^{27}$ reported on their four year experience in 65 patients with AVMs using SRS for smaller lesions $(<3 \mathrm{~cm}$ diameter) and Spetzler-Martin grades 1 and 2. The mean dose to the periphery of the AVM nidus was $21 \mathrm{~Gy}$. They reported an $84 \%$ complete obliteration rate based on 27 out of 32 patients who had post-treatment angiography with a minimum of two years of follow-up.

Subsequently, a number of institutions have reported obliteration rates following linear accelerator-based radiosurgery ${ }^{15-19,26}$. Zabel et al ${ }^{18}$ treated 110 patients with linear accelerator-based radiosurgery. The actuarial complete obliteration rate was $67 \%$ after four years. Young et $\mathrm{al}^{26}$ reported an angiographically confirmed obliteration rate of $60 \%$ in a series of 50 patients.

Whilst there are no randomised controlled trials comparing obliteration rates with either Gamma Knife or linear acceleratorbased treatment, Orio et $\mathrm{al}^{28}$ assessed treatment outcome in 96 patients treated with linear accelerator-based SRS and 91 patients treated with Gamma Knife SRS at the same institution.

Table 2: Results of statistical analysis using Cox proportional hazards

\begin{tabular}{lcc}
\hline Parameter & $\begin{array}{c}\text { Cox proportional hazards, } \\
\text { univariate, } \mathbf{p} \text { value }\end{array}$ & $\begin{array}{c}\text { Cox proportional hazards, } \\
\text { multivariate, } \mathbf{p} \text { value }\end{array}$ \\
\hline Age & 0.126 & 0.714 \\
Spetzler-Martin grade & 0.224 & 0.864 \\
Previous embolization & 0.293 & 0.891 \\
Location & 0.466 & 0.779 \\
Prescribed dose & 0.002 & 0.099 \\
Dose to isocentre & 0.022 & 0.586 \\
Lesion diameter & 0.449 & 0.079 \\
Lesion volume & 0.091 & 0.067 \\
\hline
\end{tabular}


Table 3: Results of testing parameters for association with failure to obliterate

\begin{tabular}{lccc}
\hline Parameter & Log-rank test, $\mathbf{p}$ & Cut-off value & $\begin{array}{c}\text { Actuarial rate of } \\
\text { obliteration, } \%\end{array}$ \\
\hline Location & 0.458 & $\mathrm{~N} / \mathrm{A}$ & $\mathrm{N} / \mathrm{A}$ \\
Spetzler Martin grade, 1/2 & 0.810 & $\mathrm{~N} / \mathrm{A}$ & $\mathrm{N} / \mathrm{A}$ \\
vs. 3/4 & 0.295 & $\mathrm{~N} / \mathrm{A}$ & $\mathrm{N} / \mathrm{A}$ \\
Previous embolization & 0.004 & $>20 \mathrm{~Gy}$ & 100 \\
Prescribed dose, Gy & & $\leq 20 \mathrm{~Gy}$ & 77.5 \\
& 0.004 & $>25 \mathrm{~Gy}$ & 91.7 \\
Dose to isocentre, Gy & $\mathrm{N} / \mathrm{S}$ & $\mathrm{N} / \mathrm{G}$ & 78.2 \\
Lesion diameter & 0.048 & $>6.4 \mathrm{cc}$ & $\mathrm{N} / \mathrm{A}$ \\
Lesion volume & & $\leq 6.4 \mathrm{cc}$ & 61.9 \\
& & & 90.1 \\
\hline
\end{tabular}

Notes: N/S - not significant; N/A - not applicable. * While log-rank test resulted in a p-value of 0.048 , it should be noted that only 10 patients were in the group with lesion volume $>6.4 \mathrm{cc}$.

The estimated complete obliteration rate at five years was $66 \%$ overall with obliteration rates of $60 \%$ in the linear accelerator group and $72 \%$ in the group treated with Gamma Knife. The difference was not statistically significant $(\mathrm{p}=0.97)$. Late toxicity occurred in $8 \%$ of patients in both groups $(\mathrm{p}=0.61)$. Post treatment haemorrhage in the latent period between treatment and obliteration, however, occurred in $13 \%$ of the gamma knife group and $6.2 \%$ of the linac-based treatment group $(\mathrm{p}=0.05)$.

Various studies have attempted to assess predictors of complete obliteration following SRS. The strongest predictor of obliteration in our series was dose to the margin $(p=0.002$ on univariate analysis) with patients prescribed $>20$ Gy significantly more likely to achieve complete obliteration ( $\mathrm{p}=0.004 \log$-rank test). This finding is in keeping with Flickinger et $\mathrm{al}^{25}$ who assessed the relationship of dose and volume to obliteration. Multivariate logistic regression analysis of 197 patients who had undergone treatment with Gamma Knife revealed a significant independent correlation with minimum dose $(\mathrm{p}=0.04)$. On the other hand, they found no evidence of a correlation with either volume or maximum dose which contrasts with our own findings. Log-rank test demonstrated a significantly lower rate of obliteration for lesions $>6.4 \mathrm{cc}(\mathrm{p}=0.048)$. However, numbers were small at this cut point and, consequently, this result may be unreliable.

Of note, we found no evidence that lesion location was a predictor of obliteration on univariate analysis $(\mathrm{p}=0.385)$. This is in contrast to the findings of Zabel et $\mathrm{al}^{18}$ who demonstrated an association between obliteration rates and location on univariate analysis $(\mathrm{p}<0.004)$, although not on multivariate analysis. However, it is important to note that lesion location also correlated with prescribed dose, with lower doses being applied to lesions in eloquent areas. It is, therefore, possible that this finding was simply a function of marginal dose as outlined above.

Furthermore, we found no evidence that either SpetzlerMartin grade or a previous history of embolization was associated with obliteration rates. The Spetzler-Martin grading scale was initially devised as a means of predicting morbidity and mortality following surgical resection of AVMs and, whilst the scale has been validated by a number of surgical centres as a reliable predictor of microsurgical outcomes ${ }^{29-31}$, its use as a predictor of outcome following SRS remains controversial. A number of studies have demonstrated correlation with outcome post-SRS ${ }^{18,19}$. Zabel et al ${ }^{18}$ found that Spetzler-Martin grade $1 / 2$ vs. 3/4 was the only variable to predict for obliteration on both univariate and multivariate analysis. However, no correlation was evident in the large series of 220 patients treated by Gamma knife assessed by Pollock et $\mathrm{al}^{32}$. Meanwhile, Schlienger et $\mathrm{al}^{33}$, reporting results from 169 patients treated with linear accelerator-based SRS, found that absence of prior embolization was an independent factor on multivariate analysis predicting successful treatment.

One limitation of our study is that only 48 patients out of a total of 79 treated were available for analysis. The majority of patients lost to analysis were excluded because they did not

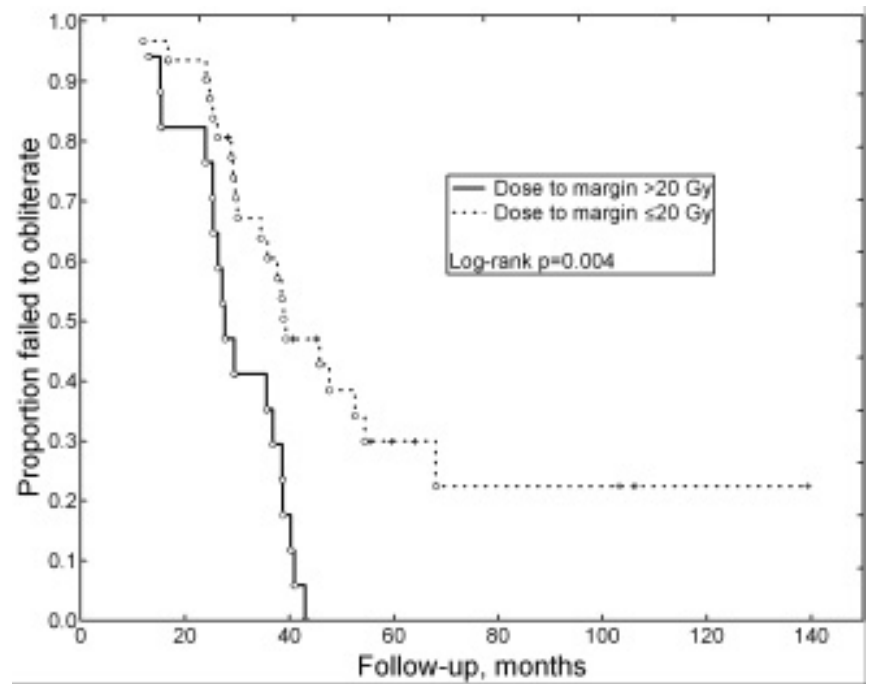

Figure 3: Actuarial proportion failed to obliterate according to prescribed dose to margin $\leq$ or $>20$ Gy. 
undergo post-treatment digital subtraction angiography. This is considered the gold standard approach for the assessment of nidus obliteration with a specificity of $100 \%$, compared to only $80 \%$ for $\mathrm{MRI}^{25}$. Whilst there is no reason to believe that there is any difference between those who underwent angiography and those that did not, it is possible that unanticipated factors could have led to an imbalance between the groups. Furthermore, although we found no evidence that lesion location, SpetzlerMartin grade, and previous history of embolization were associated with obliteration, it may simply be that our sample size was too small to detect an effect.

\section{Conclusion}

The various reported series in the literature suggest a number of different factors are predictive of complete obliteration of AVMs following radiosurgery. However, differing definitions of volume and complete obliteration makes direct comparison between these series difficult. This study demonstrates that complete obliteration of the nidus following linear acceleratorbased stereotactic radiosurgery for AVMs appears to be most closely related to the prescribed marginal dose. In particular, a marginal dose of $>20 \mathrm{~Gy}$ is strongly associated with obtaining complete obliteration of the AVM nidus.

\section{REFERENCES}

1. Mandybur TI, Nazek M. Cerebral arteriovenous malformations: a detailed morphological and immunohistochemical study using actin. Arch Pathol Lab Med. 1990;114(9):970-3 .

2. Friedlander RM. Arteriovenous malformations of the brain. N Engl J Med. 2007;356(26):2704-12.

3. ApSimon HT, Reef H, Phadke RV, Popovic EA. A population-based study of brain arteriovenous malformation: long-term treatment outcomes. Stroke. 2002;33(12):2794-800.

4. Perret G, Nishioka H. Report on the cooperative study of intracranial aneurysm and subarachnoid haemorrhage. Section VI. Arteriovenous malformations: an analysis of 545 cases of craniocerebral arteriovenous malformations and fistulae reported to the cooperative study. J Neurosurg. 1966;25(4): 467-90.

5. Monteiro JM, Rosas MJ, Correia AP, Vaz AR. Migraine and intracranial vascular malformations. Headache. 1993;33(10): 563-5.

6. Brown RD, Wiebers DO, Torner JC, O'Fallon WM. Incidence and prevalence of intracranial vascular malformations in Olmsted County, Minnesota, 1965 to 1992. Neurology. 1996;46(4): 949-52.

7. Brown RD, Wiebers DO, Torner JC, O'Fallon WM. Frequency of intracerebral hemorrhage as a presenting symptom and subtype analysis: a population-based study of intracranial vascular malformations in Olmsted County, Minnesota. J Neurosurg. 1996;85(1):29-32.

8. Crawford PM, West CR, Chadwick DW, Shaw MD. Arteriovenous malformations of the brain: natural history in unoperated patients. J Neurol Neurosurg Psychiatry. 1986;49(1):1-10.

9. Ondra SL, Troupp H, George ED, Schwab K. The natural history of symptomatic arteriovenous malformations of the brain: a 24 year follow-up assessment. J Neurosurg. 1990; 73(3): 387-91.

10. Stapf C, Mast H, Sciacca RR, et al. Predictors of hemorrhage in patients with untreated brain arteriovenous malformation. Neurology. 2006;66(9):1350-5.

11. Ogilvy CS, Stieg PE, Awad I, et al. Recommendations for the management of intracranial arteriovenous malformations: a statement for healthcare professionals from a special writing group of the stroke council, American Stroke Association. Stroke. 2001;32(6): 1458-71.
12. Spetzler RF, Martin NA. A proposed grading system for arteriovenous malformations. J Neurosurg. 1986;65(4):476-83.

13. Steiner L, Leksell L, Forster DMC, Greitz T, Backlund EO. Stereotactic radiosurgery in intracranial arteriovenous malformations. Acta Neurochir (Wien). 1974;Suppl 21:195-209.

14. Lunsford LD, Kondziolka D, Flickinger JC, et al. Stereotactic radiosurgery for arteriovenous malformations of the brain. $\mathrm{J}$ Neurosurg. 1991;75(4):512-24.

15. Colombo F, Pozza F, Chiergo G. Linear accelerator radiosurgery of cerebral arteriovenous malformations; an update. Neurosurgery. 1994;34(1): 14-21.

16. Friedman WA, Bova FJ, Bollampally S, Bradshaw MS. Analysis of factors predictive of success or complications in arteriovenous malformations radiosurgery. Neurosurgery. 2003;52(2):296-308.

17. Skjøth-Rasmussen J, Roed H, Ohlhues L, Jespersen B, Juhler M. Complications following linear accelerator based stereotactic radiation for cerebral arteriovenous malformations. Int J Radiat Oncol Biol Phys. 2010;77(2):542-7.

18. Zabel A, Milker-Zabel S, Huber P, Shultz-Ertner D, Schlegel W, Debus J. Treatment outcome after linac-based radiosurgery in cerebral arteriovenous malformations: retrospective analysis of factors affecting obliteration. Radiother Oncol. 2005;77(1): 105-10.

19. Andrade-Souza YM, Zadeh G, Ramani M, Scora D, Tsao MN, Schwartz ML. Testing the radiosurgery-based arteriovenous malformation score and the modified Spetzler-Martin grading system to predict radiosurgical outcome. J Neurosurg. 2005;103 (4):642-8

20. Kaplan EL, Meier P. Nonparametric estimation from incomplete observations. J Am Stat Assoc. 1958;53:457-81.

21. Wegner RE, Oysul K, Pollock BE, et al. A modified radiosurgerybased arteriovenous malformation grading scale and its correlation with outcomes. Int J Radiat Oncol Biol Phys. 2011 Mar 15;79(4):1147-50. Epub 2010 Jun 3.

22. Coffey R, Nichols D, Shaw E. Stereotactic radiosurgical treatment of cerebral arteriovenous malformations. Gamma Unit Radiosurgery Study Group. Mayo Clin Proc. 1995;70(3):214-22.

23. Engenhart R, Wowra B, Debus J, et al. The role of high-dose singlefraction irradiation in small and large intracranial arteriovenous malformations. Int J Radiat Oncol Biol Phys. 1994;30(3):521-9.

24. Friedman W, Bova F. Linear accelerator radiosurgery for arteriovenous malformations. J Neurosurg. 1992;77(6):832-41.

25. Flickinger JC, Pollock BE, Kondziolka D, Lunsford LD. A doseresponse analysis of arteriovenous malformation obliteration after radiosurgery. Int J Radiat Oncol Biol Phys. 1996;36(4): 873-9.

26. Young C, Summerfield R, Schwartz M, O’Brien P, Ramani R. Radiosurgery for arteriovenous malformations: the University of Toronto Experience. Can J Neurol Sci. 1997;24(2):99-105.

27. Pollock BE, Lunsford LD, Kondziolka D, Maitz A, Flickinger JC. Patient outcomes after stereotactic radiosurgery for "operable" arteriovenous malformations. Neurosurgery. 1994;35(1):1-8.

28. Orio P, Stelzer KJ, Goodkin R, Douglas JG. Treatment of arteriovenous malformations with linear accelerator-based radiosurgery compared with gamma knife surgery. J Neurosurg. 2006 Dec;105 Suppl:58-63.

29. Hamilton MG, Spetzler RF. The prospective application of a grading system for arteriovenous malformations. Neurosurgery. 1994;34(1):2-7.

30. Hartmann A, Stapf C, Hofmeister C, et al. Determinants of neurological outcome after surgery for brain arteriovenous malformation. Stroke. 2000;31(10):2361-4.

31. Heros RC, Korosue K, Diebold PM. Surgical excision of cerebral arteriovenous malformations: late results. Neurosurgery. 1990; 26(4):570-8.

32. Pollock BE, Flickinger JC, Lunsford LD, Maitz A, Kondziolka D. Factors associated with successful arteriovenous malformation radiosurgery. Neurosurgery. 1998;42(6):1239-47.

33. Schlienger M, Atlan D, Lefkopoulos D, et al. Linac radiosurgery for cerebral arteriovenous malformations: results in 169 patients. Int J Radiat Oncol Biol Phys. 2000;46(5):1135-42. 